\title{
Factors Correlating to the Development of Hepatitis C Virus Infection among Drug Users-Findings from a Systematic Review and Meta-Analysis
}

\author{
Biao Zhou ${ }^{1,+}$, Gao Feng Cai ${ }^{1,+}$, Hua Kun Lv ${ }^{1,2,+}$, Shuang Fei Xu ${ }^{1}$, Zheng Ting Wang ${ }^{1}$, \\ Zheng Gang Jiang ${ }^{1}$, Chong Gao $\mathrm{Hu}^{1, *}$ and Yong Di Chen ${ }^{1, *}$ \\ 1 Department of Scientific Research and Information Management, Zhejiang Provincial Center for Disease \\ Control and Prevention, 3399 Binsheng Road, Hangzhou 310051, China \\ 2 Department of Immunization Planning, Zhejiang Provincial Key Laboratory of Infectious Disease Vaccine \\ and Prevention and Control, 3399 Binsheng Road, Hangzhou 310051, China \\ * Correspondence: chghu@cdc.zj.cn (C.G.H.); ydchen@cdc.zj.cn (Y.D.C.); Tel: +86-571-8711-5104 (Y.D.C.) \\ + These authors contributed equally to the work.
}

Received: 23 June 2019; Accepted: 30 June 2019; Published: 2 July 2019

\begin{abstract}
Hepatitis $C$ remains a significant public health threat. However, the main routes of transmission have changed since the early 1990s. Currently, drug use is the main source of hepatitis $C$ virus $(\mathrm{HCV})$ infection, and some measures have been successively implemented and additional studies have been published. However, the factors correlating with HCV infection failed to clearly define. Our study pooled the odds ratios (ORs) with $95 \%$ confidence intervals (CIs) and analyzed sensitivity by searching data in the PubMed, Elsevier, Springer, Wiley, and EBSCO databases. Publication bias was determined by Egger's test. In our meta-analysis, HCV-infected and non-HCV-infected patients from 49 studies were analyzed. The pooled ORs with $95 \%$ CIs for study factors were as follows: Injecting drug use $10.11(8.54,11.97)$; sharing needles and syringes $2.24(1.78,2.83)$; duration of drug use $>5$ years $2.39(1.54,3.71)$; unemployment $1.50(1.22,1.85)$; commercial sexual behavior $1.00(0.73$, $1.38)$; married or cohabiting with a regular partner $0.88(0.79,0.98)$, and sexual behavior without a condom $1.72(1.07,2.78)$. This study found that drug users with histories of injecting drug use, sharing needles and syringes, drug use duration of $>5$ years, and unemployment, were at increased risk of $\mathrm{HCV}$ infection. Our findings indicate that sterile needles and syringes should be made available to ensure safe injection. In view of that, methadone maintenance treatment can reduce or put an end to risky drug-use behaviors, and should be scaled up further, thereby reducing HCV infection.
\end{abstract}

Keywords: drug use; hepatitis C virus; risk factor; meta-analysis

\section{Introduction}

Hepatitis $\mathrm{C}$ is a viral infectious disease caused by the $\mathrm{HCV}$, which is characterized by diffuse liver damage [1]. In 2003, the World Health Organization (WHO) estimated that the global prevalence of HCV infection was about $3.0 \%$, with about 3-4 million new infections every year, about 130-150 million chronic infections worldwide, and about 672,000 deaths annually from acute viral hepatitis $C$ infections and hepatitis C-related liver cancer and cirrhosis [2]. At present, the new curative treatment for HCV infection, e.g., directly acting antiviral, was available and convinced in safety, and tolerability [3-5].

However, the main route of HCV infection has changed since the early 1990s. Before the 1990s, blood transfusions and the use of contaminated blood products were the main sources of HCV infection [2-6]. Whereas currently, drug use is the main source of HCV infection in most developed and developing countries [2], and statistics have shown that over 50\% of drug users are intravenous drug users [7-9], with an estimated 12 million injecting drug users worldwide [10]. HCV infection rates have 
been increasing since 2006 in some areas, especially among the younger population [9]. In addition, in the last 10 years, the number of new drug users has been increasing and there are various ways of drug use [11-14]. Pan et al. also showed that the club drug users had a high prevalence of HCV infection, as well as people with high-frequency unprotected sexual behavior and less available intervention services [15]. These findings suggest that new drugs have become a new threat to human health.

In fact, in recent times, the number of global drug users has increased rapidly, from 185 million in 2004 to 250 million in 2015 [10,16]. Similarly, the number of registered drug users in China has risen rapidly, from 70,000 in 1990 to 3 million in 2015 [17]. In view of this significant population of drug users and the risk of cross infection with HCV among drug users, the impact of HCV infection among this population remains significant and constitutes a major health burden.

In recent years, some practical measures and strategies have been implemented to tackle the spread of infections among drug users, such as publicizing health information, making condoms available in public places, providing needle/syringe exchange centers, as well as opening methadone maintenance treatment clinics that help reduce risky drug-use behaviors thereby reducing the risk of transmission of blood-borne infections [8,18-25]. However, the rates of HCV infection remain high among drug users $[25,26]$. Many factors influence the development of HCV infection among drug users, such as injecting behavior, sharing needles and/or syringes, the duration of drug use, and high-risk sexual behavior [27-35].

In 2006, Xia et al. performed meta-analysis on data collected from drug users in China to determine factors that correlate with the occurrence of HCV infection [26], and Stone et al. performed another meta-analysis for incarceration history and risk of $\mathrm{HCV}$ acquisition among people who injected drugs in 2018 [36]. In another study, Hagan et al. collected data from published or released reports between January 1989 and December 2006 and data from scientific conferences between December 2006 April 2010, and meta-analyzed the effects of risk-reduction interventions [25]. They concluded that combined substance-use treatment and support for safe injection were the most effective interventions for reducing HCV seroconversion. These findings implied that appropriate intervention can prevent $\mathrm{HCV}$ infection among injection drug users. Studies have also demonstrated that the hazards posed by certain risk factors can be controlled. However, this meta-analysis was performed on a limited number of studies and limitations were imposed as a result of literature being unavailable. For example, in 2004, Lin et al. completed a quasi-experiment design in a controlled community intervention study that included a needle and syringe exchange program, peer education and health education, provision of free needles and syringes, and the collection of used needles, which was implemented for 10 months to injecting drug users in an intervention community, but no intervention measures were implemented in a control community for comparison [37]. A number of other studies investigating factors correlating to HCV infection in drug users have been published since 2006 [27,28,38-77]; however, the contribution of each of the factors identified in such studies remains unclear or in some cases is even contradictory.

\section{Materials and Methods}

\subsection{Literature Search Strategy}

Searches were performed in specified databases on the BoKu data service platform. We used the following search terms "Hepatitis C or HCV" and "drug use or drug addiction" in the search field "Title/Abstract," and searched six international databases, namely PubMed, OVID, Springer, Wiley, Elsevier, and EBSCO. We also used the search terms "Hepatitis C or "HCV" and "drug use or drug addiction" in the search field "Abstract," and searched the Chinese Medical Journal Database and Chinese National Knowledge Infrastructure. The searches were completed in the last week of March 2019. 


\subsection{Inclusion and Exclusion Criteria}

The eligibility criteria for the studies included in this meta-analysis were: (1) The study is an original research; (2) the study was an observational study with specific temporal and geographic characteristics; (3) the study was published with the full text available; (4) all cases and controls were drug users and the source of research objects was clearly stated; (5) major influencing factors were reported; and (6) hepatitis $C$ was diagnosed by the national diagnostic criteria that existed at that time [78].

Literature was excluded from the meta-analysis when: (1) Based on the data reported, the odds ratio (OR) with $95 \%$ confidence interval $(\mathrm{CI})$ could not be achieved by calculating the major influencing factors; (2) the literature duplicated the same research; (3) according to the source of the research objects, the province (state) was used as the screening repeated research object analysis unit and for studies with the same or cross research objects, only one of the studies was included and the others were excluded; and (4) according to the declaration by Ebrahim et al., the literature satisfying the number of items in the corresponding research type declaration was less than half the total number of items $[79,80]$.

\subsection{Data Extraction}

A pre-made form was used for data extraction. The literature was assessed one-by-one and the form was completed by two trained reviewers. The following data were extracted from the qualified studies: First author, year of the study, location, sample size, the number of drug users in the $\mathrm{HCV}$-infected group and the non-HCV-infected group, the number of males and females or the male to female ratio, and age distribution among drug users.

Discrepancies between the assessment results acquired by the two reviewers were resolved by checking the original documents and discussing.

\subsection{Sensitivity Analysis}

In this meta-analysis, the studies with the maximum weight were omitted from the subgroup analysis. The remaining studies were pooled, and the pooled $\mathrm{OR}_{\text {weight }}$ values with $95 \%$ CIs for each study factor were obtained. The pooled $\mathrm{OR}_{\text {weight }}$ values were then compared with the pooled ORs before being omitted from the study.

\subsection{Statistical Analysis}

In this meta-analysis, the main indicators were the ORs with $95 \%$ CIs. Following a heterogeneity test, the fixed effects model was used to analyze factors without heterogeneity for the different studies and the random effect model was used to analyze factors with heterogeneity using the Review Manager 5.1 software. (Cochrane Collaboration, Rigshospitalet, Denmark). Heterogeneity was evaluated using Cochran's chi-square test with a significance level of $\alpha=0.1$ and using $\mathrm{I}^{2}$ statistics with heterogeneity accepted as $\mathrm{I}^{2} \leq 50 \%$ [81]. In this meta-analysis, $\mathrm{I}^{2} \leq 50 \%$ was accepted. The Egger's test was performed using the software Stata version 11.0 (Stata Corp., College Station, TX, USA), with a significance level of $\alpha=0.05$.

\section{Results}

\subsection{Literature Search}

Based on the inclusive criteria and exclusive criteria, all articles were retrieved and carefully reviewed to assess the eligibility. Forty-nine eligible studies were identified after a screening of 1109 . The selection of studies for the meta-analysis is shown in Figure 1 [82]. 


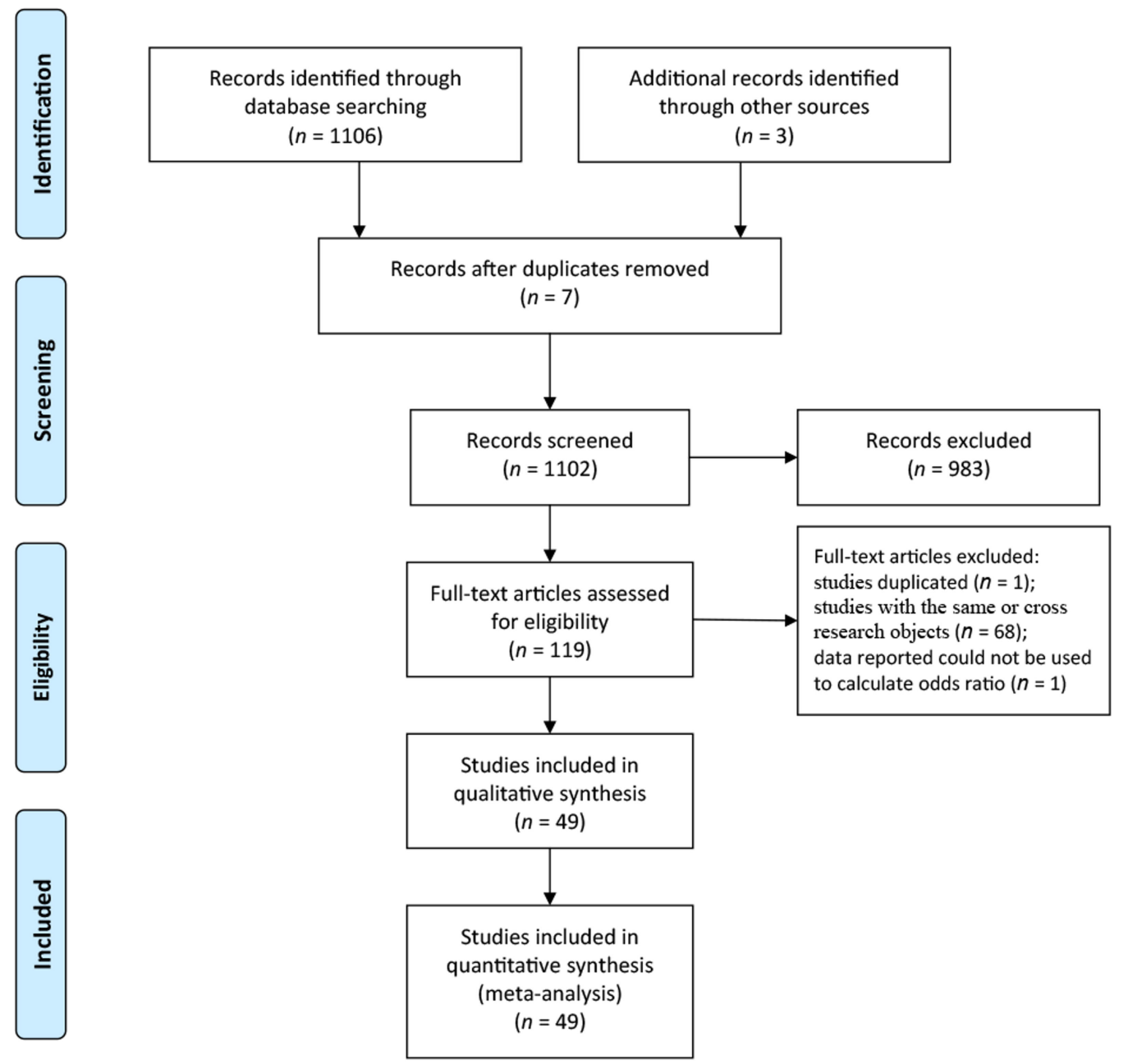

Figure 1. A flow chart of the studies selection process.

\subsection{Characteristics of the Studies}

Among the forty-nine studies, the 10 study factors used to pool ORs with $95 \%$ CIs were as follows: Injecting drug use (43 studies, 53,860 cases, 69,747 controls); sharing needles and syringes (33 studies, 40,777 cases, 23,361 controls); duration of drug use $>5$ years (12 studies, 10,282 cases, 8,794 controls); unemployment ( 6 studies, 8,361 cases, 5,420 controls); sex (male) (39 studies, 57,403 cases, 72,922 controls); education level $\leq 9$ years ( 29 studies, 46,931 cases, 61,841 controls); sexual behavior without a condom (15 studies, 10,032 cases, 24,156 controls); Han ethnic group (15 studies, 12,014 cases, 16,129 controls); married or cohabiting with a regular partner (26 studies, 46,626 cases, 62,107 controls); commercial sexual behavior (14 studies, 9,698 cases, 28,505 controls). Among the forty-nine studies, the proportion of 4 studies (injecting only) was $8.16 \%$, the proportion of 2 studies (non-injecting) was $4.08 \%$, and the proportion of 43 studies (injecting and non-injecting) was $87.76 \%$.

The characteristics of all studies evaluated in this meta-analysis are shown in Table 1. 
Table 1. Characteristics of the studies.

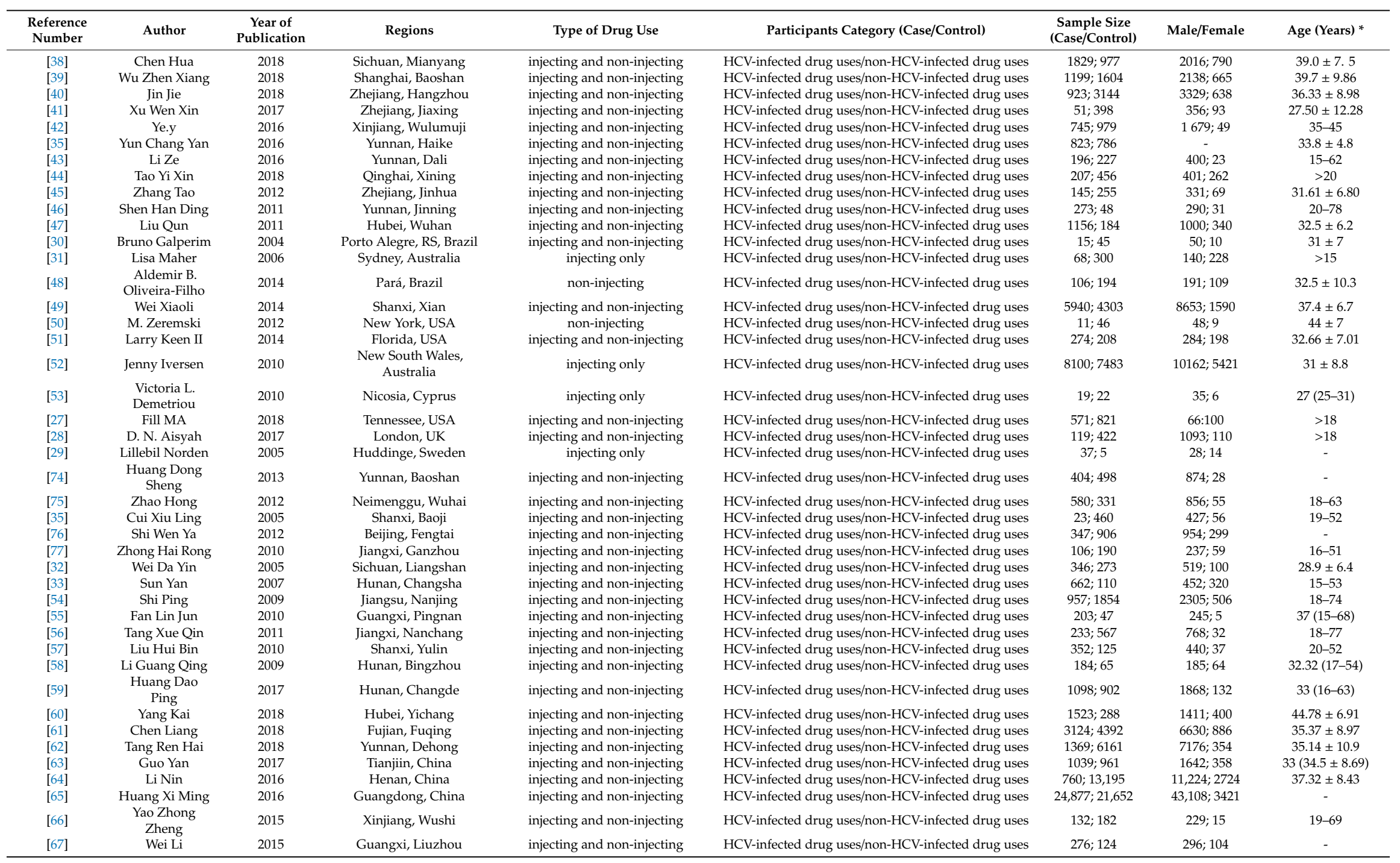


Table 1. Cont.

\begin{tabular}{|c|c|c|c|c|c|c|c|c|}
\hline $\begin{array}{c}\text { Reference } \\
\text { Number }\end{array}$ & Author & $\begin{array}{c}\text { Year of } \\
\text { Publication }\end{array}$ & Regions & Type of Drug Use & Participants Category (Case/Control) & $\begin{array}{c}\text { Sample Size } \\
\text { (Case/Control) }\end{array}$ & Male/Female & Age (Years) \\
\hline [68] & Jin Hui Ya & 2015 & Gansu, Lanzhou & injecting and non-injecting & HCV-infected drug uses/non-HCV-infected drug uses & $41 ; 189$ & $120 ; 110$ & $39.7-9.1$ \\
\hline [69] & Ma Ji Xiong & 2014 & Gansu, Baiying & injecting and non-injecting & $\mathrm{HCV}$-infected drug uses/non-HCV-infected drug uses & $82 ; 506$ & $548 ; 40$ & $30.06 \pm 6.3$ \\
\hline [70] & Pu Li Fang & 2015 & Yunnan, Kaiyuan & injecting and non-injecting & HCV-infected drug uses/non-HCV-infected drug uses & $239 ; 36$ & $209 ; 66$ & $41.6 \pm 6.0$ \\
\hline [71] & Li Feng & 2015 & Beeijing, Changping & injecting and non-injecting & HCV-infected drug uses/non-HCV-infected drug uses & $139 ; 472$ & $504 ; 107$ & $>20$ \\
\hline [73] & Feng Yan Jie & 2014 & Hebei, Qinhuangdao & injecting and non-injecting & HCV-infected drug uses/non-HCV-infected drug uses & $332 ; 304$ & $577 ; 59$ & $>20$ \\
\hline
\end{tabular}




\subsection{Results of Pooled ORs}

In this meta-analysis, the pooled ORs with $95 \%$ CIs for study factors were as follows: Injecting drug use $10.11(8.54,11.97)$; sharing needles and syringes $2.24(1.78,2.83)$; duration of drug use $>5$ years 2.39 (1.54, 3.71); unemployment $1.50(1.22,1.85)$; commercial sexual behavior $1.00(0.73,1.38)$; sex (male) $1.04(0.91,1.18)$; married or cohabiting with a regular partner $0.88(0.79,0.98)$; Han ethnic group 0.94 $(0.73,1.20)$; sexual behavior without a condom $1.72(1.07,2.78)$; and education level $\leq 9$ years $1.05(0.92$, 1.21).

The pooled ORs with their 95\% CIs for study factors are detailed in Figures 2-4, and the axes of the figures mean $\mathrm{OR}=1$.

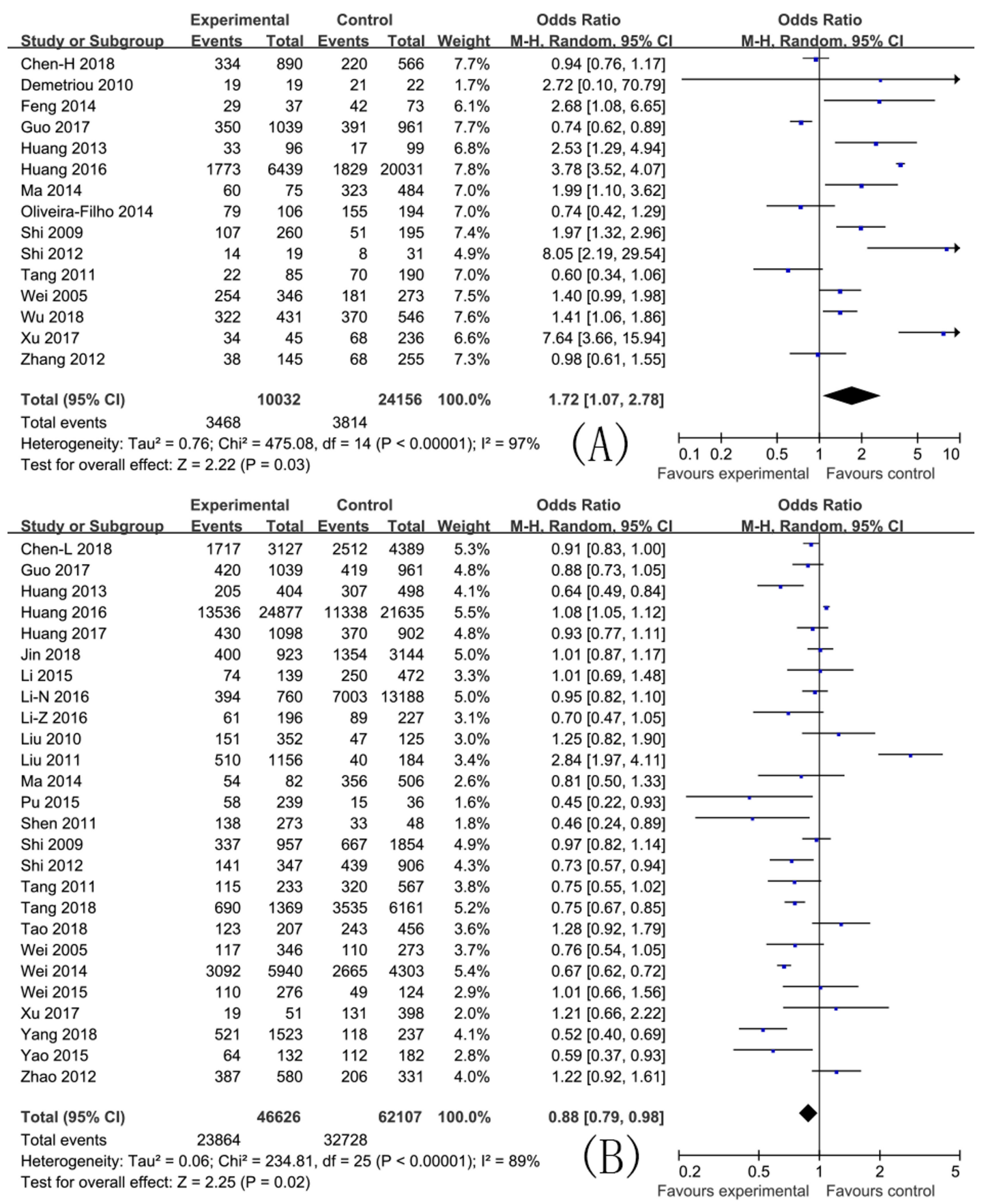

Figure 2. Effects of pooled ORs for factors correlating to the development of HCV infection among drug users ((A) sexual behavior without a condom; and (B) married or cohabiting with a regular partner). 


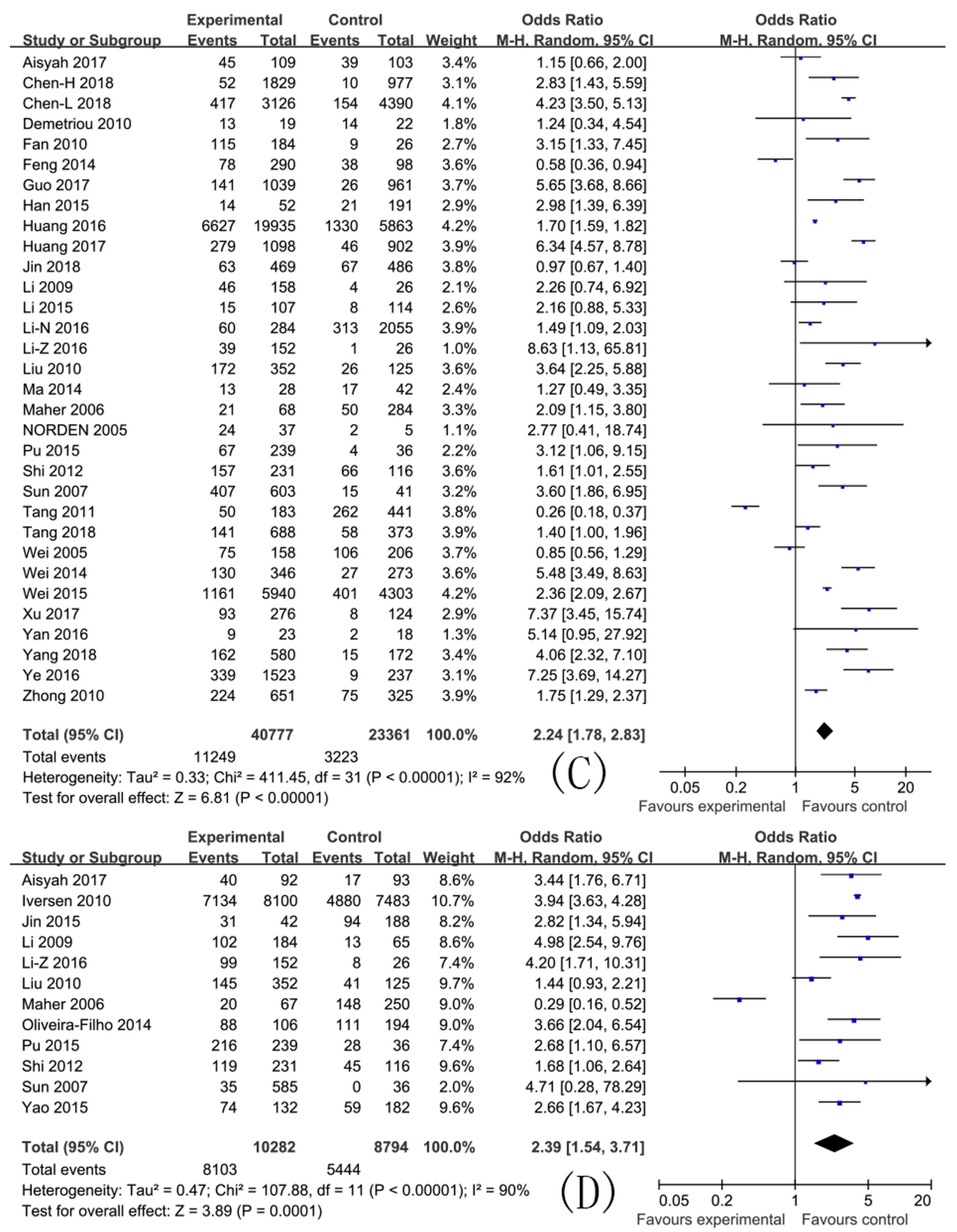

Figure 3. Effects of pooled ORs for factors correlating to the development of HCV infection among drug users ((C) Sharing needles and syringes; and (D) Duration of drug use $>5$ years). 


\begin{tabular}{|c|c|c|c|c|c|c|c|c|c|c|}
\hline Study or Subgroup & \multicolumn{2}{|c|}{ Experimental } & \multicolumn{2}{|c|}{ Control } & Weight & $\begin{array}{c}\text { Odds Ratio } \\
\text { M-H, Random, } 95 \% \mathrm{Cl}\end{array}$ & \multicolumn{3}{|c|}{$\begin{array}{c}\text { Odds Ratio } \\
\mathrm{M}-\mathrm{H}, \text { Random, } 95 \% \mathrm{Cl}\end{array}$} & \multirow[b]{2}{*}{$\rightarrow$} \\
\hline Aisyah 2017 & 109 & 119 & 103 & 410 & $2.0 \%$ & $32.49[16.38,64.45]$ & & & & \\
\hline Chen-H 2018 & 1625 & 1829 & 264 & 977 & $2.8 \%$ & $21.51[17.56,26.35]$ & & & & $\rightarrow$ \\
\hline Chen-L 2018 & 2460 & 3099 & 1223 & 4368 & $2.9 \%$ & $9.90[8.88,11.04]$ & & & & * \\
\hline Cui 2005 & 4 & 23 & 31 & 460 & $1.3 \%$ & $2.91[0.93,9.09]$ & & & & \\
\hline Fan 2010 & 184 & 203 & 26 & 47 & $1.9 \%$ & $7.82[3.72,16.46]$ & & & & \\
\hline Feng 2014 & 290 & 332 & 98 & 304 & $2.5 \%$ & $14.51[9.70,21.72]$ & & & & $=$ \\
\hline Fill-MA 2018 & 276 & 571 & 149 & 821 & $2.7 \%$ & $4.22[3.31,5.37]$ & & & $\leftarrow$ & \\
\hline Galperim 2004 & 14 & 15 & 2 & 45 & $0.4 \%$ & $301.00[25.33,3576.60]$ & & & & $\rightarrow$ \\
\hline Guo 2017 & 836 & 1039 & 168 & 961 & $2.8 \%$ & $19.44[15.50,24.38]$ & & & & $\rightarrow$ \\
\hline Han 2015 & 42 & 52 & 21 & 191 & $1.7 \%$ & $34.00[14.90,77.61]$ & & & & \\
\hline Huang 2013 & 287 & 404 & 97 & 498 & $2.7 \%$ & $10.14[7.45,13.81]$ & & & & $\rightarrow$ \\
\hline Huang 2016 & 19973 & 24877 & 5825 & 21635 & $2.9 \%$ & $11.05[10.59,11.54]$ & & & & $\cdot$ \\
\hline Huang 2017 & 792 & 1098 & 214 & 902 & $2.8 \%$ & $8.32[6.80,10.19]$ & & & & 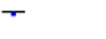 \\
\hline Jin 2015 & 1 & 42 & 9 & 188 & $0.5 \%$ & $0.49[0.06,3.94]$ & & & & \\
\hline Jin 2018 & 472 & 919 & 489 & 3133 & $2.8 \%$ & $5.71[4.86,6.71]$ & & & - & \\
\hline Keen-II 2014 & 204 & 248 & 67 & 234 & $2.4 \%$ & $11.56[7.50,17.80]$ & & & & \\
\hline Li 2009 & 158 & 184 & 26 & 65 & $2.0 \%$ & $9.12[4.77,17.40]$ & & & & \\
\hline Li 2015 & 107 & 139 & 114 & 472 & $2.4 \%$ & $10.50[6.71,16.43]$ & & & & \\
\hline Li-N 2016 & 285 & 758 & 2039 & 13165 & $2.8 \%$ & $3.29[2.82,3.84]$ & & & $T$ & \\
\hline Li-Z 2016 & 152 & 196 & 26 & 227 & $2.3 \%$ & $26.71[15.74,45.31]$ & & & & \\
\hline Liu 2010 & 213 & 352 & 53 & 125 & $2.5 \%$ & $2.08[1.38,3.15]$ & & & 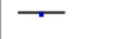 & \\
\hline Liu 2011 & 1074 & 1156 & 58 & 184 & $2.5 \%$ & $28.45[19.39,41.76]$ & & & & \\
\hline Ma 2014 & 28 & 82 & 42 & 506 & $2.2 \%$ & $5.73[3.29,9.98]$ & & & & \\
\hline Pu 2015 & 216 & 239 & 15 & 36 & $1.8 \%$ & $13.15[5.97,28.96]$ & & & & \\
\hline Shen 2011 & 267 & 273 & 38 & 48 & $1.3 \%$ & $11.71[4.03,34.06]$ & & & & \\
\hline Shi 2009 & 798 & 957 & 564 & 1854 & $2.8 \%$ & $11.48[9.43,13.98]$ & & & & $\rightarrow$ \\
\hline Shi 2012 & 231 & 347 & 116 & 906 & $2.7 \%$ & $13.56[10.09,18.24]$ & & & & $\leftarrow$ \\
\hline Sun 2007 & 473 & 662 & 19 & 110 & $2.3 \%$ & $11.99[7.11,20.21]$ & & & & \\
\hline Tang 2011 & 50 & 232 & 126 & 567 & $2.6 \%$ & $0.96[0.66,1.39]$ & & & & \\
\hline Tang 2018 & 688 & 1369 & 373 & 6161 & $2.8 \%$ & $15.68[13.51,18.19]$ & & & & $T$ \\
\hline Tao 2018 & 158 & 207 & 206 & 456 & $2.6 \%$ & $3.91[2.70,5.66]$ & & & 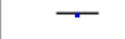 & \\
\hline Wei 2005 & 235 & 346 & 92 & 273 & $2.6 \%$ & $4.17[2.97,5.84]$ & & & & \\
\hline Wei 2014 & 5385 & 5940 & 2097 & 4303 & $2.9 \%$ & $10.21[9.18,11.35]$ & & & & * \\
\hline Wei 2015 & 262 & 276 & 48 & 124 & $2.0 \%$ & $29.63[15.50,56.63]$ & & & & \\
\hline Wu 2018 & 779 & 1199 & 352 & 1604 & $2.8 \%$ & $6.60[5.58,7.80]$ & & & 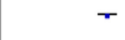 & 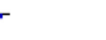 \\
\hline Xu 2017 & 23 & 51 & 18 & 398 & $1.9 \%$ & $17.34[8.39,35.86]$ & & & & \\
\hline Yan 2016 & 580 & 794 & 172 & 815 & $2.8 \%$ & $10.13[8.05,12.75]$ & & & & - \\
\hline Yang 2018 & 1396 & 1523 & 104 & 237 & $2.6 \%$ & $14.06[10.27,19.25]$ & & & & $\leftarrow$ \\
\hline Yao 2015 & 112 & 132 & 45 & 182 & $2.2 \%$ & $17.05[9.52,30.54]$ & & & & $\rightarrow$ \\
\hline Ye 2016 & 651 & 745 & 325 & 979 & $2.7 \%$ & $13.94[10.81,17.96]$ & & & & $\leftarrow$ \\
\hline Zhang 2012 & 73 & 145 & 42 & 255 & $2.4 \%$ & $5.14[3.23,8.18]$ & & & & \\
\hline Zhao 2012 & 553 & 580 & 145 & 331 & $2.4 \%$ & $26.27[16.87,40.92]$ & & & & $\longrightarrow$ \\
\hline Zhong 2010 & 94 & 106 & 33 & 190 & $1.9 \%$ & $37.27[18.35,75.68]$ & & & & \\
\hline Total (95\% Cl) & & 53860 & & 69747 & $100.0 \%$ & $10.11[8.54,11.97]$ & & & & $\boldsymbol{\gamma}$ \\
\hline Total events & 42610 & & 16074 & & & & & & & \\
\hline $\begin{array}{l}\text { Heterogeneity: } \mathrm{Tau}^{2}= \\
\text { Test for overall effect: }\end{array}$ & $\begin{array}{l}.25 ; \mathrm{Chi}^{2} \\
=26.88\end{array}$ & $\begin{array}{l}=887.80 \\
(P<0.00\end{array}$ &,$d f=42$ & $(P<0.0$ & $0001) ; 1^{2}=$ & $=95 \%$ & & 0.2 & 5 & 20 \\
\hline
\end{tabular}

Figure 4. Effects of pooled ORs for injecting drug use correlating to the development of HCV infection among drug users.

\subsection{Results of Heterogeneity Evaluation}

A heterogeneity test showed that variations among studies for the pooled ORs with $95 \%$ CIs for factors including injecting drug use, sharing needles and syringes, drug use duration of $>5$ years, unemployment, commercial sexual behavior, sex (male), married or cohabiting with a regular partner, Han ethnic group, sexual behavior without a condom, and an education level of $\leq 9$ years were statistically significant $(p<0.10)$. The effects of these factors were then pooled using the random effect model. These results are detailed in Figures 2-4.

\subsection{Publication Bias}

In this meta-analysis, a funnel plot for the duration of drug use was symmetrical, with the axis of symmetry $(\mathrm{OR}=1)$ being to the right of center, as detailed in Figure 5. The results of Egger's test for study factors were all $p>0.05$, as detailed in Table 2 . 


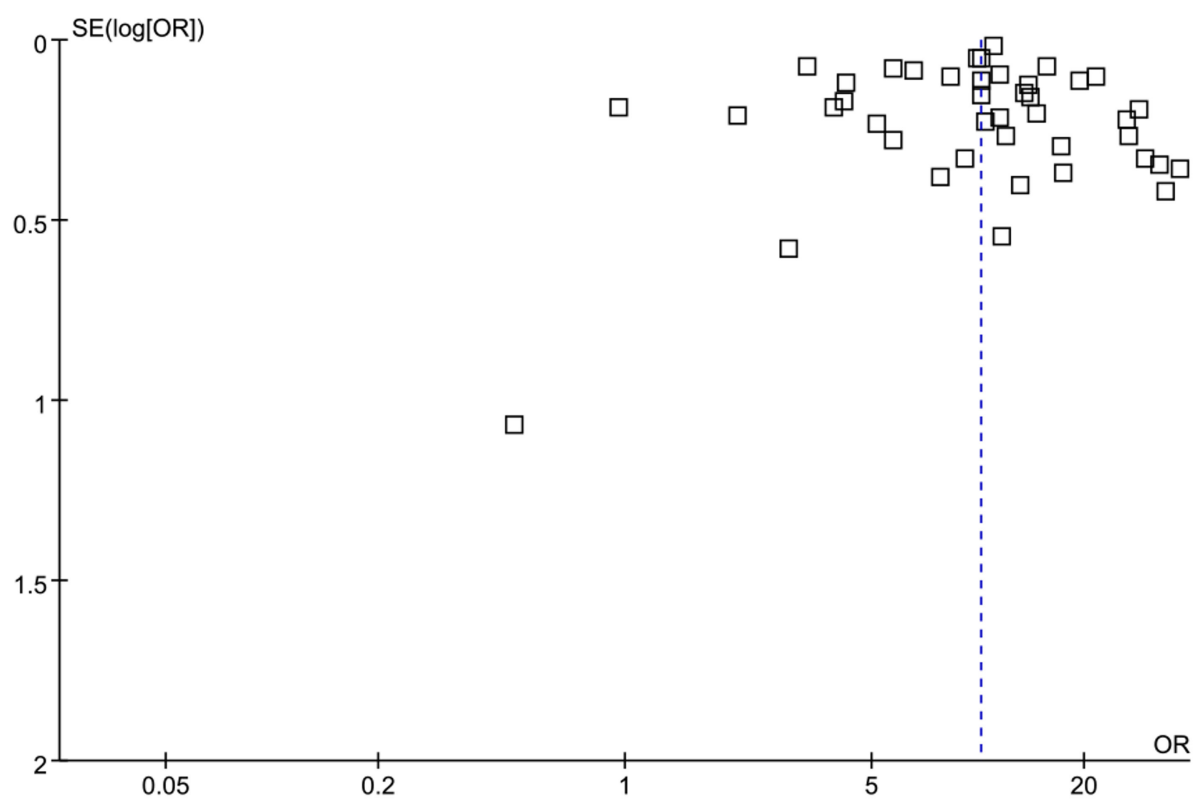

Figure 5. A funnel plot of the articles publication for the duration of drug use. 
Table 2. The subgroup characteristics of the study factors associated with HCV infection among drug users after omitting the studies with the maximum weight value for the ORs in the subgroup analysis and the results of Egger's test.

\begin{tabular}{|c|c|c|c|c|c|c|c|}
\hline \multirow{2}{*}{ Subgroup Analyses by Study Factors (1) * } & \multirow{2}{*}{$\begin{array}{l}\text { Pooled OR with 95\% CI } \\
\text { before Reference Omitted (2) }\end{array}$} & \multirow{2}{*}{$\begin{array}{l}\text { Pooled OR with } 95 \% \mathrm{CI} \text { after } \\
\text { Reference Omitted (3) }\end{array}$} & \multirow{2}{*}{$\begin{array}{l}\text { Qualitative Comparison: } \\
\text { Reversal of Pooled OR with } \\
95 \% \text { CI ((2) and (3) Compared) }\end{array}$} & \multirow{2}{*}{$\begin{array}{l}\text { Quantitative Comparison: Similar } \\
\text { Values of Pooled OR with 95\% CI } \\
\text { ((2) and (3) Compared) }\end{array}$} & \multirow{2}{*}{$\begin{array}{l}\text { Reference } \\
\text { Omitted }\end{array}$} & \multicolumn{2}{|c|}{ Egger's Test } \\
\hline & & & & & & $t$ & $p$-Value \\
\hline Education level $\leq 9$ years & $1.05(0.92,1.21)$ & $1.05(0.91,1.21)$ & No & Yes & [49] & -0.77 & 0.450 \\
\hline Sexual behavior without a condom & $1.72(1.07,2.78)$ & $1.50(1.10,2.03)$ & No & Yes & [65] & -1.79 & 0.097 \\
\hline Sharing needles and syringes & $2.244(1.78,2.83)$ & $2.31(1.66,3.23)$ & No & Yes & {$[65,67]$} & 0.86 & 0.395 \\
\hline Han ethnic group & $0.94(0.73,1.20)$ & $0.96(0.70,1.30)$ & No & Yes & [62] & 0.27 & 0.788 \\
\hline Married or cohabiting with a regular partner & $0.88(0.79,0.98)$ & $0.87(0.78,0.97)$ & No & Yes & [65] & -1.53 & 0.139 \\
\hline Sex (male) & $1.04(0.91,1.18)$ & $1.02(0.90,1.15)$ & No & Yes & {$[52,65]$} & -1.01 & 0.319 \\
\hline Commercial sexual behavior & $1.00(0.73,1.38)$ & $0.95(0.61,1.47)$ & No & Yes & {$[39,40,64]$} & -0.79 & 0.446 \\
\hline Unemployment & $1.50(1.22,1.85)$ & $1.48(1.07,2.06)$ & No & Yes & [49] & -0.23 & 0.831 \\
\hline Duration of drug use $>5$ years & $3.49(3.24,3.75)$ & $3.47(3.22,3.74)$ & No & Yes & [58] & -1.78 & 0.106 \\
\hline Injecting drug use & $10.11(8.54,11.97)$ & $10.21(8.03,12.97)$ & No & Yes & {$[49,61,65]$} & -0.35 & 0.731 \\
\hline
\end{tabular}

Note: *: (1)—means Subgroup Analyses by Study Factors; (2)—means Pooled OR with 95\% CI before Reference Omitted; (3)—means Pooled OR with 95\% CI after Reference Omitted. 


\subsection{Sensitivity Analysis}

In view of the reliability of the pooled ORs using the random effect model for terms including injecting drug use, drug use duration of $>5$ years, unemployment, commercial sexual behavior, sex (male), married or cohabiting with a regular partner, Han ethnic group, sharing needles and syringes, sexual behavior without a condom, and an education level of $\leq 9$ years, we omitted studies with the highest weights, pooled the remaining studies, and acquired the $\mathrm{OR}_{\text {weight }}$ values with $95 \%$ CIs. These pooled values were compared with those obtained before the studies were omitted for qualitative and quantitative comparisons and no major changes in the pooled ORs with $95 \%$ CIs were observed for any of the study factors, as detailed in Table 2.

\section{Discussion}

This study found that drug users with a history of injecting drug use, and/or sharing needles/syringes, drug use duration of $>5$ years, and/or unemployment, and/or sexual behavior without a condom, were at increased risk of HCV infection, whereas drug users who were married or cohabiting with a regular partner were at decreased risk of developing HCV infection. This study also found that, for drug users (male), commercial sexual behavior, Han ethnicity, an education level of $\leq 9$ years, did not affect the risk of developing $\mathrm{HCV}$ infection.

In general, exposure to $\mathrm{HCV}$-contaminated needles and syringes increases the risk of $\mathrm{HCV}$ infection, and such exposure may be common among injecting drug users [83,84]. The findings of our meta-analysis confirmed that drug users with histories of injecting drug use were at increased risk of HCV infection, and this result was consistent with those of Xia et al. [26]. However, the findings of this meta-analysis that injecting drug users with a history of sharing needles/syringes were at increased risk of developing HCV infection was not consistent with the results reported in the meta-analysis by Xia et al. in 2008, and this may be related to the fact that only three studies on sharing needles were pooled in Xia et al.'s study and that this small sample size led to low test efficiency and unreliable results [26].

The findings of this meta-analysis also showed that drug use duration of $>5$ years was a risk factor for developing HCV infection, which may relate to the longer the duration of drug use, the greater the opportunity to be exposed to HCV-contaminated needles or goods, potentially leading to an infection. This result was consistent with the findings of a previous meta-analysis report [26].

In view of that, methadone maintenance treatment can reduce or put an end to risky drug-use behaviors. This discovery suggests methadone maintenance treatment should be scaled up further so as to shorten the duration of drug use and reduce the risk of HCV infections [24].

The findings of this meta-analysis also showed that sexual behavior without a condom was a risk factor for developing HCV infection. The results of the meta-analysis by Xia et al. in 2008's meta-analysis reported that high-risk sexual practices were strongly associated with injecting drug behavior [26], but the magnitude of high-risk sexual behavior or the correlation between high-risk sexual behavior and drug-injecting behavior and their contribution to the occurrence of HCV infection could not be determined, thus requiring further study. In our study, there was a high proportion of injecting drug behavior and high-risk sexual behavior among the drug users, but related information on individual cases was not available.

The use of amphetamine-type stimulants is currently on the rise, as is unprotected sexual behavior becoming more common and leads to a high prevalence of HCV infection among the club drug user $[17,85-87]$, strategies therefore need to be implemented to try to reduce such behaviors and to help to reduce the progression of HCV infection. In addition, further meta-analyses for club drug use will be done when there is enough literature.

The findings of this meta-analysis also showed that unemployment among drug users increased the risk of developing HCV infection, and this finding was consistent with the results of meta-analysis of human immunodeficiency virus (HIV) infection, which has a similar transmission route, among drug users [88]. 
The findings of our meta-analysis showed that drug users who were married or cohabiting with a regular partner were at decreased risk of developing $\mathrm{HCV}$ infection, and this finding was consistent with the results of meta-analysis published by Hagan et al. [27], and this may be related to the fact that these drug users had fewer sexual partners and fewer opportunities to be exposed to HCV-infected bodily fluids. However, the findings of this meta-analysis also showed that drug users with commercial sexual behavior, namely having multiple sexual partners, were not at increased risk of developing $\mathrm{HCV}$ infection, and this may be related to using club drug use with a shorter duration of drug use [15], although this requires further investigation.

The findings of this meta-analysis also showed that those of Han ethnicity, compared with those of other minority ethnic groups, were not at increased or decreased risk of developing HCV infection, and this finding was consistent with the results of meta-analysis published by Xia et al. [26]. Our findings also showed that drug users with an education level of $\leq 9$ years were not at increased or decreased risk of developing HCV infection; however, this finding was inconsistent with that of a previous meta-analysis of HIV infection, which has a similar transmission route among drug users [88].

The limitations of this study were that even though the ORs of the study factors were pooled using a random-effect method, heterogeneity among studies might have influenced the findings. In addition, some study factors, for example, some racial classifications (white or black) were not available to be pooled. Lastly, few studies could be unavailable because of language limitations, in view of that, this meta-analysis' publication bias was not statistically significant, and thus, this aspect influenced findings slightly.

\section{Conclusions}

This study found that drug users with histories of injecting drug use, sharing needles and syringes, drug use duration of $>5$ years, and unemployment, were confirmed to be at increased risk of HCV infection. Our findings indicate that high-risk drug users should be closely monitored and sterile needles and syringes should be made available to ensure safe injection. In view of that, methadone maintenance treatment can reduce or put an end to risky drug-use behaviors and should be scaled up further so as to shorten the duration of drug use, thereby reducing HCV infection.

Author Contributions: Study design: C.G.H., B.Z., G.F.C., H.K.L., Y.D.C. Statistical analysis and interpretation: H.K.L., Y.D.C. Manuscript preparation: G.F.C., S.F.X., Z.G.J., Z.T.W., Y.D.C. Critical review of manuscript: B.Z., Y.D.C., C.G.H. All authors read and approved the final manuscript.

Funding: This work was supported by National Health and Family Planning Commission of the People's Republic of China (No. WKJ-ZJ-1917).

Acknowledgments: The authors appreciate the collaboration of staff from our public opinion monitoring and health communication research team.

Conflicts of Interest: The authors declare no conflict of interest.

\section{Abbreviations}

The following abbreviations are used in this manuscript:

$\begin{array}{ll}\text { HCV } & \text { Hepatitis C Virus } \\ \text { CI } & \text { Confidence Interval } \\ \text { OR } & \text { Odds Ratio } \\ \text { M-H } & \text { Mantel-Haenszel } \\ \text { WHO } & \text { World Health Organization }\end{array}$

\section{References}

1. Li, J.; Chen, J.; Zhuang, H. Epidemiology of Hepatitis C. J. Pract. Liver Dis. 2012, 15, 376-379.

2. WHO. Guidelines for the Screening Care and Treatment of Persons with Hepatitis C Infection; World Health Organization: Geneva, Switzerland, 2003. 
3. Falade-Nwulia, O.; Suarez-Cuervo, C.; Nelson, D.R.; Fried, M.W.; Segal, J.B.; Sulkowski, M.S. Oral Direct-Acting Agent Therapy for Hepatitis C Virus Infection: A Systematic Review. Ann. Intern. Med. 2017, 166, 637-648. [CrossRef] [PubMed]

4. Millman, A.J.; Nelson, N.P.; Vellozzi, C. Hepatitis C: Review of the Epidemiology, Clinical Care, and Continued Challenges in the Direct Acting Antiviral Era. Curr. Epidemiol. Rep. 2017, 4, 174-185. [CrossRef] [PubMed]

5. Jakobsen, J.C.; Nielsen, E.E.; Feinberg, J.; Katakam, K.K.; Fobian, K.; Hauser, G.; Poropat, G.; Djurisic, S.; Weiss, K.H.; Bjelakovic, M. Direct-acting antivirals for chronic hepatitis C. Cochrane Database Syst. Rev. 2017. [CrossRef] [PubMed]

6. WHO. Guidelines for the Screening, Care and Treatment of Persons with Hepatitis C Infection. 2014. Available online: https://www.who.int/hepatitis/publications/hepatitis-c-guidelines/en/ (accessed on 20 August 2017).

7. Jia, Z.S. Review and reflection: 30 years of research on prevention and treatment of hepatitis C. J. Clin. Hepatobiliary Dis. 2015, 31, 1803-1807.

8. Zheng, E.D.; Gao, L.M.; Peng, X.; Xie, T.S.; Liu, H.Y.; Sun, Y.Q.; Huang, J.; Li, H. HIV and HCV infection situation and associated risk factors among injecting drug users: A meta-analysis. Chin. J. Dis. Control. Prev. 2017, 21, 1271-1277.

9. Zhuang, X.; Liang, Y.; Chow, E.P.F.; Wang, Y.F.; Wilson, D.P.; Zhang, L. HIV and HCV prevalence among entrants to methadone treatment clinics in China: A systematic review and meta-analysis. BMC Lnfect. Dis. 2012, 12, 130-134. [CrossRef] [PubMed]

10. Zibbell, J.; Iqbal, K.; Patel, R.; Suryaprasad, A.; Sanders, K.; Moore-Moravian, L.; Serrecchia, J.; Blankenship, S.; Ward, J.; Holtzman, D.; et al. Increases in hepatitis $C$ virus infection related to injection drug use among persons aged $\leq 30$ years-Kentucky, Tennessee, Virginia, and West Virginia, 2006-2012. MMWR Morb. Mortal. Wkly. Rep. 2015, 64, 453-459. [PubMed]

11. United Nations Office on Drugs and Crime. World Drug Report 2017. Available online: http://www.nncc626. com/2018-06/11/c_129892175.htm (accessed on 21 August 2017).

12. Degenhardt, L.; Copeland, J.; Dillion, P. Recent trends in the use of "club drugs": All Australian review. Subst. Use Misuse 2005, 40, 1241-1257. [CrossRef]

13. United Nations Officeon Drugs and Crime (UNODC). 2011 Patterns and Trends of Amphetamine-Type Stimulants and Other Drugs: Asia and the Pacific [EB/OL]. (2012-10-18) (2014-12-21). Available online: http: //www.unode.org/documents/scientific/Asia_and_the_Pacific_2011_Regional_ATS_Report.pdf (accessed on 25 August 2017).

14. Fernández, M.; Bowen, G.; Varga, L.; Collazo, J.; Hernandez, N.; Perrino, T.; Rehbein, A. High rates of club drug use and risky sexual practices among Hispanic men who have sex with men in Miami, Florida. Subst. Use Misuse 2005, 40, 1347-1363. [CrossRef]

15. Parsons, J.; Kelly, B.; Wells, B. Difierences in club drug use between heterosexual and lesbian/bisexual females. Addict. Behav. 2006, 31, 2344-2350. [CrossRef]

16. Pan, X.H.; Jiang, J.; He, H.; Chen, L.; Yang, J.Z.; Zhang, H.B.; Wang, N. Survey of prevalence of HIV infection, syphilis and HCV infection and related risk behaviors among club drug users in Zhejiang, 2011. Chin. J. Epidemiol. 2015, 36, 934-11.

17. Liu, H.M. World Drug Report 2004. Available online: http://www.people.com.cn/GB/guandian/183/2281/327 6/2607166.htmI (accessed on 23 August 2017).

18. Legal Daily. Nearly 3 Million Drug Addicts Have Been Registered in China. Available online: http: //legal.people.eom.en/n/2015/0619/el88502-27184718.htm (accessed on 19 December 2015).

19. Puente, M.T.; Cuevas, J.; Jimenez-Hernandez, N.; Bracho, M.; García-Robles, I.; Wrobel, B.; Carnicer, F.; Olmo, J.D.; Ortega, E.; Moya, A.; et al. Genetic variability in hepatitis C virus and its rule in antiviral treatment response. J. Viral Hepat. 2008, 15, 188-200. [CrossRef] [PubMed]

20. Tan, Y.; Wei, Q.H.; Chen, L.J.; Chan, P.C.; Lai, W.S.; He, M.L.; Kung, H.F.; Lee, S.S. Molecular epidemiology of $\mathrm{HCV}$ monoinfection and $\mathrm{HIV} / \mathrm{HCV}$ eoinfection in injection drug users in Liuzhou, Southern China. PLoS ONE 2008, 3, e3608. [CrossRef] [PubMed]

21. Yang, Y.; Guan, Q.Z.; Xu, Y.; Chen, S.D.; Wu, B.W. Serum epidemiology of hepatitis $\mathrm{c}$ and $\mathrm{b}$ virus infection in drug users. Zhonghua Shi Yan He Lin Chuang Bing Du Xue Za Zhi 1999, 13, 247-251. [PubMed]

22. Pang, L.; Mi, G.D.; Wang, C.H.; Luo, W.; Rou, K.M.; Li, J.H.; Wu, Z.Y. Evaluation of first 8 pilot methadone maintenance treatment clinics in China. Zhonghua Shi Yan He Lin Chuang Bing Du Xue Za Zhi 2007, 21, $2-5$. 
23. Dole, V.P.; Nyswander, M. A medical treatment for diacetylmorphine (heroin) addiction. JAMA 1965, 193, 646. [CrossRef]

24. Wu, Z. Landmark Government Methadone Maintenance Program in Mainland China. In Proceedings of the 15th International AIDS Conference, Bangkok, Thailand, 13 July 2004.

25. Wu, Z. Methadone maintenance program in mainland China: From pilot to scale-up. In Proceedings of the International Conference on the Reduction of Drug Related Harm, Belfast, Northern Ireland, UK, 20 March 2005.

26. Hagan, H.; Pouget, E.R.; Jarlais, D.C.D. Meta-Analysis of HCV Prevention for PWID. JID 2011, $204,74-83$. [CrossRef]

27. Xia, X.; Luo, J.; Bai, J.L.; Yu, R.B. Epidemiology of hepatitis C virus infection among injection drug users in China: Systematic review and meta-analysis. Public Health 2008, 122, 990-1004. [CrossRef]

28. Fill, M.A.; Sizemore, L.A.; Rickles, M.; Cooper, K.C.; Buecker, C.M.; Mullins, H.L.; Hofmeister, M.G.; Abara, W.E.; Foster, M.A.; Asher, A.K.; et al. Epidemiology and risk factors for hepatitis C virus infection in a high-prevalence population. Epidemiol. Infect. 2018, 146, 508-515. [CrossRef]

29. Aisyah, D.N.; Shallcross, L.; Hayward, A.; Aldridge, R.W.; Hemming, S.; Yates, S.; Ferenando, G.; Possas, L.; Garber, E.; Watson, J.M.; et al. Hepatitis C among vulnerable populations: A seroprevalence study of homeless, people who inject drugs and prisoners in London. J. Viral Hepat. 2018, 25, 1260-1270. [CrossRef] [PubMed]

30. Nordén, L.; Lidman, C. Differentiated risk behaviour for HIV and hepatitis among injecting drug users (IDUs). Scand. J. Infect. Dis. 2005, 37, 493-497. [CrossRef] [PubMed]

31. Galperim, B.; Cheinquer, H.; Stein, A.; Fonseca, A.; Lunge, V.; Ikuta, N. Intranasal cocaine use does not appear to be an independent risk factor for HCV infection. Addiction 2004, 99, 497-502. [CrossRef] [PubMed]

32. Maher, L.; Jalaludin, B.; Chant, K.G.; Jayasuriya, R.; Sladden, T.; Kaldor, J.M.; Sargent, P.L. Incidence and risk factors for hepatitis C seroconversion in injecting drug users in Australia. Addiction 2006, 101, 1499-1509. [CrossRef]

33. Wei, D.Y.; Yang, Y.; Ruan, Y.H.; Zeng, G.H.; Han, L.; Liang, S.; Zhang, J.H.; Yin, L.; Zhang, L.; Qin, G.M.; et al. HCV Prevalence and Risk Factors among Drug Users in Xichang County of Sichuan, China. J. Prev. Med. Inf. 2005, 21, 135-140.

34. Sun, Y.; Zhang, Y.; Chen, W.; Guan, L.; Liu, H.; Tan, M.J.; Li, D.Q.; Dai, W.P.; Huang, M.S. Hepatitis C Virus Infection among Drug Users. Occup. Health 2007, 23, 881-884.

35. Yun, C.Y.; Wu, J.C.; Liu, J.C. Investigation on HCV infection and influencing factors among drug users in haikou area. Hainan Med. J. 2016, 27, 1878-1880.

36. Cui, X.L.; Li, Z. Investigation on the infection status of HBV, HCV, HIV and syphilis among 483 drug addicts in baoji city in 2005. Prev. Med. Trib. 2005, 11, 169-171.

37. Stone, J.; Fraser, H.; Lim, A.G.; Walker, J.G.; Ward, Z.; Mac Gregor, L.; Trickey, A.; Abbott, S.; Strathdee, S.A.; Abramovitz, D.; et al. Incarceration history and risk of HIV and hepatitis C virus acquisition among people who inject drugs: A systematic review and meta-analysis. Lancet Infect. Dis. 2018, 18, 1397-1440. [CrossRef]

38. Lin, P.; Fan, Z.F.; Yang, F.; Wu, Z.Y.; Wang, Y.; Liu, Y.Y.; Ming, Z.Q.; Li, W.J.; Luo, W.; Fu, X.B.; et al. Effect evaluation of needle exchange project for community drug users in Guangdong. Chin. J. Prev. Med. 2004, 38, 305-309.

39. Chen, H.; Zhao, X.H.; Liao, K.K.; Zhang, J.Y. Analysis of current situation of HCV infection among drug users in Mianyang City. Chin. J. Health Educ. 2018, 34, 258-261.

40. Wu, Z.Q.; Liu, X.F.; Wang, N.; Yang, X.T.; Cao, G.W. Seroprevalence of human immunodeficiency virus, hepatitis c virus, and syphilis infection their influencing factors among drug users in baoshan district of Shanghai from 2010 to 2016. Shanghai J. Prev. Med. 2018, 30, 223-229.

41. Jin, J.; Luo, Y.; Chen, J.F.; Li, X.T.; Zhang, X.L.; Xu, K. Prevalence of HIV, syphilis and HCV and their risk factors among drug users in Hangzhou. Prev. Med. 2018, 30, 248-257.

42. Xian, X.W.; Tong, Z.W.; Rui, G.; Qian, Z.Q. analysis on the status of syphilis and HCV infection and influencing factors among community drug addicts in Jiaxing City. Prev. Med. 2017, 29, 135-139.

43. Ye, Y.; Zhang, Z.; Zhao, X.L.; Tian, T.; Cai, A.; Dai, J. HIV, HCV, syphilis and their co-infection and risk factors analysis among drug users in Urumqi from 2010 to 2014. J. Xinjiang Med. Univ. 2016, 39, 1447-1452.

44. Li, Z.; Liu, J.Z.; Shen, Y.Y. Investigation on the Infection of HIV, HCV and Association High Risk Factors among Drug Users. J. Dali Univ. 2016, 1, 77-81. 
45. Tao, Y.X.; Zhao, C.; Gao, X.Y. ChengCurrent situation and influencing factors of HCV infection among drug users in xining city. Guangxi Med. J. 2018, 40, 2855-2858.

46. Zhang, T.; Ji, J.F.; Qiu, Y.W. Analysis of monitoring results of AIDS, syphilis and hepatitis c among drug addicts. Zhejiang Prev. Med. 2012, 24, 29-32.

47. Shen, H.D.; Tang, J.F.; Yang, W.; Zhao, Y. Investigation and analysis of HCV infection among methadone patients in jining county. Soft Sci. Health 2011, 25, 867-870.

48. Liu, Q. Prevalence of HCV, HIV and Syphilis Infection among Drug Addicts at the Methadone Treatment Clinic in Wuhan and Analysis of Risk Factors. Chin. J. Rehabil. 2011, 26, 356-358.

49. Oliveira-Filho, A.B.; Sawada, L.; Pinto, L.C.; Locks, D.; Bahia, S.L.; Castro, J.A.A.; Hermes, R.B.; Brasil-Costa, I.; Amaral, C.E.M.; Lemos, J.A.R. Epidemiological aspects of HCV infection in non-injecting drug users in the Brazilian state of Pará, eastern Amazon. Virol. J. 2014, 11, 38-46. [CrossRef] [PubMed]

50. Wei, X.L.; Wang, L.R.; Wang, X.L.; Li, J.S.; Li, H.X.; Jia, W. Risk Factors of Hepatitis C Virus Infection in Drug Users from Eleven Methadone Maintenance Treatment Clinics in Xi'an, China. Hepat. Mon. 2014, 14, e19061. [CrossRef] [PubMed]

51. Zeremski, M.; Makeyeva, J.; Arasteh, K.; Jarlais, D.C.D.; Talal, A.H. Hepatitis C virus-specific immune responses in noninjecting drug users. J. Viral Hepat. 2012, 19, 554-559. [CrossRef] [PubMed]

52. Keen, L., II; Khan, M.; Clifford, L.; Harrell, P.T.; Latimer, W.W. Injection and non-injection drug use and infectious disease in Baltimore City: Differences by race. Addict. Behav. 2014, 39, 1325-1333. [CrossRef] [PubMed]

53. Iversen, J.; Wand, H.; Gonnermann, A.; Maher, L.; On Behalf of the Collaboration of Australian Needle and Syringe Programs. Gender differences in hepatitis $C$ antibody prevalence and risk behaviours amongst people who inject drugs in Australia 1998-2008. Int. J. Drug Policy 2010, 21, 471-477. [CrossRef]

54. Demetriou, V.L.; van de Vijver, D.A.; Hezka, J.; Kostrikis, L.G.; Cyprus IVDU Network. Hepatitis C Infection Among Intravenous Drug Users Attending Therapy Programs in Cyprus. J. Med Virol. 2010, 82, 263-271. [CrossRef] [PubMed]

55. Shi, P.; Li, L. Survey and analysis on the HCV infection among drug users. Jiangsu Prev. Med. 2009, $20,10-13$.

56. Fan, L.J. Analysis of HIV, HCV and syphilis infection among 250 drug addicts in pingnan county. Health Heaven. Earth-Health Insp. Prev. 2010, 4, 113-115.

57. Qin, T.X. Results Analysis of HIV Sentinel Surveillance among Drug Addicts in Detention in Nanchang Area. Occup. Health 2011, 27, 2180-2184.

58. Liu, H.B.; Zhe, X.L. Study on HCV Co-infection in Yulin Drug Users. J. Med. Pest. Control. 2010, 26, 731-733.

59. Li, G.Q.; Wu, M.Q.; Yuan, S.R. Analysis of HBV, HCV infection and liver function in 249 cases of heroin addicts. Chin. J. Drug Abuse Prev. Treat. 2009, 15, 80-84.

60. Huang, D.P.; Li, Y.J.; Zhou, Y.Y.; Guan, H.J. Prevalence of HCV infection and related risk factors among drug users in Changde City. Pract. Prev. Med. 2017, 24, 330-332.

61. Yang, K.; Yang, Y.L.; Peng, G.P.; Jiang, H.L.; Li, L.L.; Tang, H. Analysis of HIV, HCV and TP Infection in Patients under Maintenance Treatment Methadone with in Yichang Urban City. Chin. J. Derm. Venereol. 2018, 32, 302-306.

62. Chen, L.; Lin, X.; Lian, Q.L.; Zhang, M.Y.; Zheng, W.X. HCV infection and related factors among drug users in Fujian Province, 2010-2015. Chin. J. AIDS STD 2018, 24, 48-52.

63. Tang, R.H.; Gao, Y.; Yang, Y.C.; Cao, Y.F.; Yang, S.J.; Ye, R.H.; Wang, J.B.; Wang, Y.K.; Duan, S.; He, N. Analysis of $\mathrm{HCV}$ infection rate and its influence factors among drug users in Dehong Prefecture, Yunnan Province. Chin. J. Prev. Med. 2018, 52, 87-91.

64. Guo, Y.; Ning, T.L.; Zhou, N. HCV inaction status and associated factors among drug users in Tianjin from 2011 to 2015. Int. J. Virol. 2017, 24, 178-184.

65. Li, N.; Wang, X.W.; Nie, Y.G.; Ma, Y.M.; Wen, J.; Fan, P.Y.; Sun, D.Y.; Zhu, Q. HCV infeetion status and related risk factors in drug users under HIV sentinel surveillance in Henan province, 2011-2015. Chin. J. Epidemiol. 2016, 37, 821-826.

66. Huang, X.M.; Lin, P.; Li, Y.; Fu, X.B. Analysis on HCV seroprevalence and related risk factors among drug users, Guangdong province, 2011-2013. Prev. Med. Trib. 2016, 22, 88-94.

67. Yao, Z.Z.; Xu, X.R.; Lei, L.J. Investigation and analysis of hepatitis c infection among drug users in usu city. Bull. Dis. Control. Prev. 2015, 30, 3-9. 
68. Wei, L.; Zhang, Y.J. Prevalence and associated risk factors of HIV, HCV and TP in drug users in Liuzhou City. Chin. J. Dis. Control. Prev. 2015, 19, 1248-1253.

69. Jin, H.Y.; Li, W.T.; Yan, L.; Fu, X.Y.; Xu, M.M.; Pu, S.D.; Liu, X.J.; He, J.C. Analysis of infection of HBV, HCV and TP and relative factors among drug addicts under compulsory rehabilitation in Lanzhou. J. Lanzhou Univ. (Med. Sci.) 2015, 41, 44-49.

70. Ma, J.X.; Liu, S.J.; Wang, Y.B.; Yang, C. Analysis of hepatitis c infection and its influencing factors among methadone addicts in baiyin outpatient clinic. Chin. J. PHM 2014, 30, 531-533.

71. Pu, L.F.; Su, Y.Y.; Wang, G.X.; Bai, J. Prevalence of HIV and HCV infections in patients receiving methadone maintenance treatment in Kaiyuan. Chin. J. Epidemiol. 2015, 36, 29-32.

72. Li, F.; Wang, H. s.; Liu, H.X.; Guo, S.Y.; Hao, Z. Hepatitis C infection and its influencing factors among drug users in Changping district of Beij ing in 2009-2013. Chin. Prev. Med. 2015, 16, 105-108.

73. Han, X.; Hou, X.Y.; Li, H.J. The present situation of AIDS, syphilis and hepatitis c among drug users in Hohhot in 2011. J. Dis. Surveill. Control. 2014, 8, 494-496.

74. Feng, Y.J.; Wang, L.; Liang, L.; Cao, N.X. The Infectious Status of HIV, HCV and Treponema pallidum Infection and Related Risk Factor in 636 Drug Users in Qinhuangdao City. Chin. J. Derm. Venereol. 2014, 18, 600-604.

75. Huang, D.S.; Zheng, W.B.; Yang, J.F.; Li, Y.P.; Hu, A.Y.; Guo, J.H.; Peng, J.Y.; Xu, Z.C.; Liu, L.; Ding, Y.; et al. Analysis of HCV ser0preVaIence and related influencing factors among drug users in HIV sentinel points, Baoshan City. Chin. J. AIDS STD 2013, 19, 279-283.

76. Zhao, H.; Ban, H.; Gao, L. Investigation on infection of hepatitis C virus among IDUs in Wuhai City from 2010 to 2011. J. Dis. Monit. Control. 2012, 6, 705-707.

77. Shi, W.Y.; Xie, Y.Y.; Liu, C. An epidemiological survey On hepatitis C virus infection among drug users in Beijing. Chin. J. AIDS STD 2012, 18, 184-188.

78. Zhong, H.R. Analysis of HIV, HCV and syphilis infection in 296 drug addicts in ganzhou city. South China J. Prev. Med. 2010, 36, 31-33.

79. National Health and Family Planning Commission of the People's Republic of China. WS 213-018 Diagnosis for hepatitis C. J. Clin. Hepatol. 2018, 34, 3-6.

80. Ebrahim, S.; Clarke, M. STROBE: New standards for reporting observational epidemiology, a chance to improve. Intern. J. Epidemiol. 2007, 36, 946-949. [CrossRef] [PubMed]

81. Strobe Statement: Strengthening the Reporting of Observational Studies in Epidemiology [EB/OL]. Available online: http://www.strobe-statement.org/index.php?id=strobe-translations (accessed on 1 May 2013).

82. Ades, A.E.; Lu, G.; Higgins, J.P. The interpretation of random-effects meta-analysis in decision models. Med. Decis. Mak. 2005, 25, 646-654. [CrossRef]

83. Moher, D.; Liberati, A.; Tetzlaff, J.; Altman, D.G.; The PRISMA Group. Preferred Reporting Items for Systematic Reviews and Meta-Analyses: The PRISMA Statement. PLoS Med. 2009, 6, e1000097. [CrossRef]

84. Schaefer, M.; Mauss, S. Hepatitis C treatment in patients with drug addiction: Clinical management of interferon-alpha-associated psychiatric side effects. Curr. Drug Abus. Rev. 2008, 1, 177-188. [CrossRef]

85. Dolan, K.A.; Shearer, J.; White, B.; Zhou, J.; Kaldor, J.; Wodak, A.D. Four-year follow-up of imprisoned male heroin users and methadone treatment:mortality, re-incarceration and hepatitis C infection. Addiction 2005, 100, 820-829. [CrossRef] [PubMed]

86. Hao, W.; Xiao, S.; Liu, T.; Young, D.; Chen, S.; Zhang, D.; Li, C.; Shi, J.; Chen, G.; Yang, K. The second National Epidemiological Survey on illicit drug use at six high-prevalence areas in China: Prevalence rates and use patterns. Addiction 2002, 97, 1305-1316. [CrossRef]

87. Zhao, M.; Du, J.; Lu, G.H.; Wang, Q.Y.; Xu, H.; Zhu, M.; McCoy, C.B. HIV sexual risk behaviors among injection drug users in Shanghai. Drug Alcohol Depend. 2006, 82 (Suppl. S1), s43-s48. [CrossRef]

88. Xing, J.N.; Qian, S.S.; Guo, W.; Li, Y.G.; Ding, Z.W.; Wang, L. Meta-analysis on risk factors of HIV infection among drug users in China. Dis. Surveill. 2013, 28, 823-828.

(C) 2019 by the authors. Licensee MDPI, Basel, Switzerland. This article is an open access article distributed under the terms and conditions of the Creative Commons Attribution (CC BY) license (http://creativecommons.org/licenses/by/4.0/). 